\title{
Infertility as the onset of Cushing's disease: is pasireotide a treatment option?
}

${ }^{1}$ Department of Endocrinology, Iuliu Hatieganu University of Medicine and Pharmacy \& Clinical County Hospital, Cluj-Napoca, Romania

${ }^{2}$ Department of Endocrinology, Cluj-Napoca Clinical County Hospital, Romania

${ }^{3}$ Department of Radiotherapy, Prof. Dr. Ion Chiricuta Oncology Institute, Cluj-Napoca, Romania

${ }^{4}$ Department of Endocrinology, Carol Davila University of Medicine and Pharmacy, Bucharest \& C.I. Parhon

National Institute of Endocrinology, Bucharest, Romania

\begin{abstract}
Introduction

Cushing's disease is a complex endocrine disorder characterized by excessive glucocorticoid secretion caused by an ACTH-secreting pituitary adenoma. Hyperandrogenism and menstrual disorders such as amenorrhea and oligomenorrhea complete the clinical picture of Cushing's syndrome. Infertility is relatively common, involving complex pathogenetic mechanisms, which differ depending on the cause of hypercortisolism. Case presentation

We present the case of a female patient diagnosed with Cushing's disease during the investigations carried out to assess infertility. After transsphenoidal adenomectomy, the patient underwent treatment with pasireotide and dopamine agonists, achieving normalization of gonadotropin and estradiol levels.

Conclusion

Current guidelines recommended transsphenoidal adenomectomy as first-line therapy in an attempt to correct hypercortisolism and restore fertility in patients with Cushing's disease. In case of relapse pasireotide and dopamine agonists can be effective in normalizing the hormonal profile.
\end{abstract}

Key words: Cushing's disease, pasireotide

\section{Mara Carsote}

Bucharest, Romania, Aviatorilor Ave 34-38, sector 1, postal code 011863 fax: +40213170607 ;

phone: +40213172041 ;

email: carsote_m@hotmail.com

\section{Introduction}

Cushing's disease is an endocrine disorder characterized by complex clinical symptoms caused by excessive cortisol secretion. In $15 \%$ of cases, hypercortisolism is ACTH-independent due to adrenal adenomas or adenocarcinomas; in $85 \%$ of cases the cause is uncontrolled pituitary or ectopic ACTH secretion. [1,2,3] These latter forms (known as Cushing's disease of the ACTH source is pituitary), account for $70 \%$ of endogenous causes of chronic hypercortisolism. [1] In most cases clinical signs and symptoms are highly suggestive for hypercortsolism defining the classic clinical picture of Cushing's syndrome. [1,2] Patients rarely present with isolated clinical signs of the disease creating difficulties in establishing an early diagnosis. The presence of menstrual disorders such as oligomenorrhea and amenorrhea, weight gain and hirsutism in adolescence could be a diagnostic trap.[1] Infertility is relatively common in Cushing's disease involving complex pathogenetic mechanisms which differ to some extent depending on the cause of hypercortisolism. [2] In both $\mathrm{ACTH}-d e p e n d e n t$ and ACTH-indepedentent forms the pathogenesis of infertility involves both increased levels of androgens and direct action of cortisol on the pituitary gland. $[1,2,3]$ In case of ACTH-secreting pituitary adenomas central hypogonadism may occur due to tumor compression of gonadotropic cells and possibly hyperprolactinemia. [3] Apart from surgery 
pasireotide is a second line treatment option proven to restore gonadal function in patients with Cushing's disease. [4]

\section{Case report}

We present the case of a 37 year-old patient who was referred at the age of 31 for primary infertility. Personal history revealed menarche at the age of 13 with irregular cycle lengths (between 30-180 days) and long periods of amenorrhea. Physical exam revealed morbid obesity with central distribution, a Body Mass Index (BMI) of $55 \mathrm{~kg}$ / $\mathrm{m} 2$ with progressive weight gain starting at the age of 15 . She also presents hirsutism with a FerrimanGallway score of 12 points, purple-red abdominal striae, cervical acanthosis nigricans, heart rate of 72 per minute, blood pressure of $130 / 70 \mathrm{mmHg}$. Hormonal profile showed normal gonadotropin levels with low serum estradiol and progesterone, hyperprolactinemia and hyperandrogenism. (Table I) Abdominal ultrasound revealed normal ovarian morphollogy, linear endometrium and discrete bilateral adrenal hyperplasia. Adrenal function tests were highly suggestive of Cushing's disease: high ACTH levels, high serum cortisol with loss of diurnal variation, inadequate suppression of cortisol after the low-dose dexamethasone supression test and suppression after the high-dose dexamethasone test sugestive for Cushing's disease. (Table I)

Pituitary Magnetic Resonance Imagery (MRI) revealed the presence of a macroadenoma of 21 by 13 by $21 \mathrm{~mm}$ extending into the right cavernous sinus

Table I: Biological and hormonal parameters in 37-year old patient with Cushing's disease and infertilty

\begin{tabular}{|c|c|c|c|c|}
\hline Parameter & Before surgery & Post-surgery & Under Pasireotide & Reference Range \\
\hline FSH & 4.5 & 0.97 & 1.55 & $1.2-9 \mathrm{U} / \mathrm{L}$ \\
\hline LH & 2.3 & 0.41 & 0.25 & $0.5-12 \mathrm{U} / \mathrm{L}$ \\
\hline Estradiol & 26.3 & 14,7 & 47,6 & $27-250 \mathrm{pg} / \mathrm{ml}$ \\
\hline Progesterone & 0.1 & 0.09 & 0.10 & $0.2-1.4 \mathrm{ng} / \mathrm{ml}$ \\
\hline Total Testosterone & 1.2 & 1 & 1.1 & $0.3-0.73 \mathrm{ng} / \mathrm{ml}$ \\
\hline Prolactin & 64.3 & 4.48 & 11.3 & $2-17 \mathrm{ng} / \mathrm{ml}$ \\
\hline TSH & 1.12 & 0,15 & 0,55 & $0.5-4 \mu \mathrm{UI} / \mathrm{ml}$ \\
\hline FreeT4 & 0.52 & 0.82 & 0.9 & $0.8-1.7 \mathrm{ng} / \mathrm{dl}$ \\
\hline $\begin{array}{l}\text { Morning plasma } \\
\text { cortisol } 8 \text { a.m. }\end{array}$ & 295.2 & 230.1 & 197 & $70-225 \mathrm{ng} / \mathrm{ml}$ \\
\hline Plasma cortisol 8 p.m & 192.6 & 182 & 80 & $50-165 \mathrm{ng} / \mathrm{ml}$ \\
\hline $\mathrm{ACTH}$ & 141 & 60 & 42 & $10-50 \mathrm{pg} / \mathrm{ml}$ \\
\hline \multicolumn{5}{|l|}{ Plasma cortisol 8 a.m. } \\
\hline $2 \times 2 \mathrm{mg}$ DSM & 137.2 & & & $<18 \mathrm{ng} / \mathrm{ml}$ \\
\hline $\begin{array}{l}\text { Cortisol } 8 \text { a.m. } \\
2 \times 8 \mathrm{mg} \text { DSM }\end{array}$ & 11.3 & & & $\begin{array}{l}<50 \% \text { from baseline value } \\
\text { sugestive for Cushing's disease }\end{array}$ \\
\hline $\mathrm{AST}$ & 24 & 21 & 222 & $0-42 \mathrm{U} / \mathrm{L}$ \\
\hline ALT & 35 & 28 & 128 & $0-48 \mathrm{U} / \mathrm{lL}$ \\
\hline GGT & 42 & 89 & 369 & $9-36 \mathrm{U} / \mathrm{L}$ \\
\hline $\begin{array}{l}\text { Blood morning } \\
\text { glucose }\end{array}$ & 92 & 98 & 178 & $70-105 \mathrm{mg} / \mathrm{dl}$ \\
\hline $\begin{array}{l}\text { Hb A1c (glycated } \\
\text { hemoglobin) }\end{array}$ & & & 9.3 & $4.8-5.9 \%$ \\
\hline
\end{tabular}


and displacing the pituitary stalk. (Figure 1)

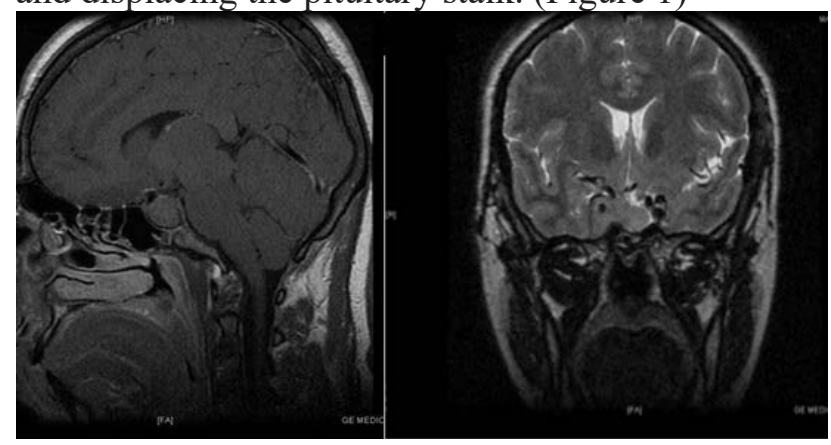

Figure 1: Pituitary macroadenoma exteds into the right cavernous sinus and in the close contact with the left one

Based on these data the diagnosis of Cushing's disease was established: an ACTH-secreting pituitary macroadenoma asociated with hyperprolactinemia, secondary ovarian insufficiency, secondary hypothyroidism. Treatment with dopamine agonists, levothyroxine and oral contraceptives was initiated after the patient looked for a second endocrine opinion in a different medical centre. Transsphenoidal adenomectomy was performed 3 months after the diagnosis. Post surgery follow-up 3 months later revealed persistence of the disease. In this context pasireotide $2 \times 600 \mathrm{mcg}$ per day was starting in association with dopamine agonist. Hormonal profile under pasireotide revealed normal serum cortisol, lower ACTH levels, normal estradiol levels but persistent secondary amenorrhea in the absence of contraceptive treatment. Pasireotide was discontinued after 12 months due to a severe hepatocytolisis syndrome and the occurrence of type 2 diabetes with poor glycemic control.

\section{Discussions}

Chronic hypercortisolism is an important cause of infertility in patients with Cushing's disease. Secondary amenorrhea and oligomenorrhea are present in approximately $75 \%$ of women with Cushing's disease as a result of gonadotropin suppression by glucocorticoid excess.[1,2,3,5] Adrenal androgens further suppress pituitary FSH and LH secretion but they also directly inhibit ovarian function. $[1,2,3,5]$ In ACTH-dependent forms we frequently encounter high levels of serum prolactin, commonly due to mixed ACTH and PRL-secreting adenomas. In case of macroadenomas hyperprolactinemia can be the result of tumor compression on the pituitary stalk. $[1,2,3,5]$

In this case the early onset of Cushing's disease, probably 2 years after menarche, associated with significant, progressive weight gain contributed to the onset of oligomenorrhea and secondary amenorrhea. At the time of diagnosis our patient already presented with pituitary macroadenoma and hyperprolactinemia. In this context low serum estradiol and progesterone levels could be the result of gonadotropin suppression by hypercortisolism but they could equally be due to suppression of hypothalamic GnRH secretion by hyperprolactinemia. In addition, hyperprolactinaemia directly inhibits estrogen and progesterone synthesis at the ovarian level. [6] Transsphenoidal adenomectomy is able to restore ovarian function both by correcting hypercortisolism and by removing compression on gonadotropic cells. [4,6] Recent studies report postoperative remission rates of $50-70 \%$ in case of macroadenomas. [4]

In our patient's case due to the large size of the adenoma and its expansion into the right cavernous sinus, complete tumor resection was not possible. Consequently the patient presented with relapse 3 months after surgery, with persistence of menstrual disorders. Since repeat surgery is associated with decreased remission rates and increased risk of hypopituitarism we decided to initiate combination therapy: pasireotide and dopamine agonists. In this situation dopamine agonists target both the correction of hyperprolactinemia, and the suppression of ACTH secretion, reported in pituitary tumors expressing dopamine receptors.[7,8] Pasireotide ensures control of hypercortisolism by inhibiting ACTH secretion and its clinical consequences. After 12 months of treatment we witnessed normalization of serum gonadotropins and estradiol but without restoring normal menstrual cycles. Treatment with pasireotide had to be discontinued due to progressive increase of liver enzymes and uncontrolled diabetes mellitus. 


\section{Gonclusion}

Pasireotide may be an alternative for restoring fertility in patients with Cushing's disease by normalizing serum cortisol and, indirectly, gonadotropin levels but as long as severe side effects are not registered. However a potential future pregnancy under pasireotide has not a clear safety profile yet.

\section{Conflict of interest}

None to declare.

\section{Acknowledgement}

We thank to the patient.

\section{References}

1. Pivonello, R., De Martino, M. C., De Leo, M., Lombardi, G., \& Colao, A. (2008). Cushing's Syndrome. Endocrinol Metab Clin North Am, 37(1), 135-149, ix. doi: 10.1016/j. ecl.2007.10.010

2. Shah, D. \& Patel, S. (2009). Hirsutism. Gynecol Endocrinol, 25 (3), 140-148.

3. Sharma, J.B., Roy, K.K., Mohanraj, P., Kumar ,S., Karmakar, D. \& Barua, J. (2009). Pregnancy outcome in pituitary tumors. Arch Gynecol
Obstet. 280 (3),401-404.

4. Poullot, A-G. \& Chevalier, N. (2013). New options in the treatment of Cushing's disease: a focus on pasireotide. Research and Reports in Endocrine Disorders. 3,31-38.

5. Aron, D.C., Schnall, A.M. \& Sheeler, L.R. Cushing's syndrome and pregnancy. Am J Obstetrics and gynecology, 162 (1),244-252.

6. Ursula, B. (2012). Hyperprolactinemia and infertility: new insight. J Clin Invest. 122 (10), 3791-3795.

7. Gadelha, M.R., Viera Neto, L. (2014). Efficacy of medical treatment in Cushing's disease: a systeamtic review, Clin Endocrinol (Oxf). 80 (1): $1-12$

8. Bertagna, X \& Guignat, L. (2013). Approach to the Cushing's disease patient with persistent/ recurrent hypercortisolism after pituitary surgery. $J$ Clin Endocrinol Metab. 98(4):1307-18. doi: 10.1210/jc.2012-3200. 